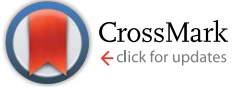

Cite this: RSC Adv., 2017, 7, 4161

Received 18th November 2016 Accepted 12th December 2016

DOI: 10.1039/c6ra27018b

www.rsc.org/advances

\title{
A red emitting of manganese-doped boron carbon oxynitride (BCNO) phosphor materials: facile approach and photoluminescence properties
}

\author{
Bebeh W. Nuryadin, ${ }^{* a}$ Fitri A. Permatasari, ${ }^{\text {b }}$ Ade Y. Nuryantini, ${ }^{c}$ Irfana D. Faryuni, ${ }^{d}$ \\ Mikrajuddin Abdullah ${ }^{b}$ and Ferry Iskandar*be
}

\begin{abstract}
BCNO (boron carbon oxynitride) phosphors have attracted attention due to their non toxicity, simple synthesis process, and high quantum efficiency. However, the tunable emission, particularly a red emission, is still challenging to achieve. In the present study, a bright red emission (emission wavelength $620 \mathrm{~nm}$ under $365 \mathrm{~nm}$ UV excitation) of a manganese-doped BCNO (BCNO:Mn) phosphor synthesized by a solid state method is reported. Without Mn-doping, the BCNO phosphor exhibited a bright blue emission that can be ascribed to the closed-shell $\mathrm{BO}^{-}$and $\mathrm{BO}^{2-}$ anions that act as luminescence center. Via $\mathrm{Mn}$-doping, a red emission was exhibited that can be ascribed to the ${ }^{4} \mathrm{~T}_{1}\left({ }^{4} \mathrm{G}\right) \rightarrow{ }^{6} \mathrm{~A}_{1}\left({ }^{6} \mathrm{~S}\right)$ transition from a new luminescence center of $\mathrm{Mn}^{2+}$ incorporated into the $\mathrm{BCNO}$ host lattice. The optimum red $\mathrm{PL}$ properties ( $\lambda_{\mathrm{em}}: 611 \mathrm{~nm}, \lambda_{\mathrm{ex}}: 365 \mathrm{~nm}$ ) were obtained with BCNO:Mn at a molar ratio of $\mathrm{Mn} / \mathrm{B}$ at $0.71 \%$ $\mathrm{mol} / \mathrm{mol}$ synthesized at $550{ }^{\circ} \mathrm{C}$. We believe that the BCNO:Mn is a promising red-emitting phosphor for white light diodes.
\end{abstract}

\section{Introduction}

Boron carbon oxynitride (BCNO) is one of the most attractive phosphor materials because of its excellent properties, such as non-toxicity, simple synthesis process, tunable color emission, and high quantum efficiency. ${ }^{1-3}$ These excellent properties of the BCNO phosphor offer a great potential application for light emitting diode (LED), panel displays, bio-imaging, and DNA labelling. ${ }^{3-5}$ The BCNO phosphor material, an intermediate material between graphite and hexagonal-BN, was first synthesized by our group using a urea combustion method. ${ }^{\mathbf{1}}$ The main PL mechanism of BCNO is thought to be due to closed-shell $\mathrm{BO}^{-}$and $\mathrm{BO}^{2-}$ anions that act as a luminescence center. Another PL mechanism of BCNO involves carbon and oxygen impurities that produce energy levels in the bandgap rather than inter-band transition or exciton emission. The original band gap of pristine BCNO was calculated to be around $5.8 \mathrm{eV}$. $^{4}$ This wide band gap leads to red photoluminescence of BCNO phosphor still being a challenge to obtain.

\footnotetext{
${ }^{a}$ Department of Physics, UIN Sunan Gunung Djati Bandung, Bandung 40614, Indonesia. E-mail: bebehwahid102@uinsgd.ac.id

${ }^{b}$ Department of Physics, Faculty of Mathematics and Natural Sciences, Institut Teknologi Bandung, Bandung 40132, Indonesia

${ }^{c}$ Department of Physics Education, UIN Sunan Gunung Djati Bandung, Bandung 40614, Indonesia

${ }^{d}$ Department of Physics, Faculty of Mathematics and Natural Sciences, Tanjungpura University, Pontianak, Indonesia

${ }^{e}$ Research Center for Nanoscience and Nanotechnology, Institut Teknologi Bandung, Bandung 40132, Indonesia. E-mail: ferry@fi.itb.ac.id
}

Several studies have been conducted concerning the attainment of red emission of the BCNO phosphor. ${ }^{5-8}$ Our group successfully obtained near red emission $(\sim 571 \mathrm{~nm})$ of BCNO by increasing the polyethylene glycol (PEG) fraction and decreasing the synthesis temperature $\left(700{ }^{\circ} \mathrm{C}\right){ }^{6}$ The increased PEG fraction led to the presence of carbon defects in the crystal lattice of the BCNO phosphor through substitution or intercalation. Zhang et al., have reported red emission $(\sim 620 \mathrm{~nm})$ by increasing the sintering temperature, heating time and the ratio of boric acid to hexamethylenetetramine. ${ }^{7}$ Increasing the sintering temperature $\left(650^{\circ} \mathrm{C}\right)$ leads to nitrogen defects that act as electron traps in the BCNO lattice. Kang et al., reported a broad emission (from $400-750 \mathrm{~nm}$ ) by converting graphene oxide into a BCNO hybrid nanosheet. ${ }^{8}$ The sheets may contain the BCNO, graphene quantum dots (GQDs), and graphene oxide. These three different chemical structures possess intrinsic state emission (electron-hole recombination, quantum size effect/ zig-zag sites) and defect state emission (surface energy traps) as a luminescence center.

Red photoluminescence has not only been attempted with BCNO but also in other phosphor materials. An alternative to overcome this challenge is the use of manganese (Mn) as the dopant in phosphor materials. ${ }^{9-11}$ Numerous studies have reported successful red emission from Mn-doped phosphors such as $\mathrm{Mn}: \mathrm{LiAlO}_{2},{ }^{9} \mathrm{Mn}: \mathrm{CaZnOS},{ }^{\mathbf{1 0}}$ and Mn:AlN. ${ }^{11}$ The Mn doped phosphors are expected to play an important role in red emission due to the $\mathrm{d}-\mathrm{d}$ transitions in $\mathrm{Mn} .{ }^{9-11}$ In addition, the presence of dopant atoms in the BCNO structure increases its quantum yield, as reported in other studies. ${ }^{12,13}$ To the best of 
our knowledge, the recent literature contains no reports regarding Mn-doping of BCNO phosphors.

In this study, we report the first synthesis of Mn doped BCNO from citric acid, boric acid, urea and manganese(II) sulfate monohydrate via a solid state method. Furthermore, we elucidated the influence of the synthesis temperature and Mn-doping concentration on the PL properties of BCNO:Mn using scanning electron microscopy (SEM), spectrofluorophotometry, and X-ray diffraction (XRD). Moreover, we considered the luminescence mechanism possibilities on the BCNO:Mn structure.

\section{Experimental}

\section{Material and synthesis}

A schematic flowchart for the manganese doped BCNO preparation via a solid-state method is shown in Fig. 1. Analytical reagents such as boric acid $\left(\mathrm{H}_{3} \mathrm{BO}_{3}\right.$, Merck Co. Ltd.), citric acid $\left(\mathrm{C}_{6} \mathrm{H}_{8} \mathrm{O}_{7}\right.$, Merck Co. Ltd.), urea $\left(\left(\mathrm{NH}_{2}\right)_{2} \mathrm{CO}\right.$, Merck Co. Ltd.), and manganese(II) sulfate monohydrate $\left(\mathrm{MnSO}_{4} \cdot \mathrm{H}_{2} \mathrm{O}\right.$, Merck Co. Ltd) were used as raw materials.

A precursor was prepared by dissolving all raw materials in $10 \mathrm{~mL}$ pure water at $70{ }^{\circ} \mathrm{C}$ under stirring at $500 \mathrm{rpm}$ for $10 \mathrm{~min}$. For all samples, the mass of boric acid, urea and citric acid were fixed at $0.5 \mathrm{~g}, 2 \mathrm{~g}$, and $0.01 \mathrm{~g}$, respectively. Moreover, doping of Mn was conducted by varying the molar ratio of manganese to boron source (Mn/B) from 0 to $2.84 \% \mathrm{~mol} / \mathrm{mol}$. After sufficient stirring, the precursor solutions were heated in an electrical furnace with the temperature varying from $500{ }^{\circ} \mathrm{C}$ to $700{ }^{\circ} \mathrm{C}$ for 30 min under ambient atmospheric pressure.

\section{Characterization}

The chemical bonding of the prepared samples was determined by the Fourier transform infrared (FTIR, Bruker Optics, Ettlingen - Germany) spectroscopy method with an Alpha Platinum ATR sampling module. The crystal structure of the prepared samples was analyzed using an X-ray diffractometer (XRD Philips Analytical PW 1710 BASED, PANalytical, Netherlands) with a $0.02^{\circ}$ step size using $\mathrm{Cu} \mathrm{K} \alpha$ radiation $(\lambda=1.5406 \AA)$. The

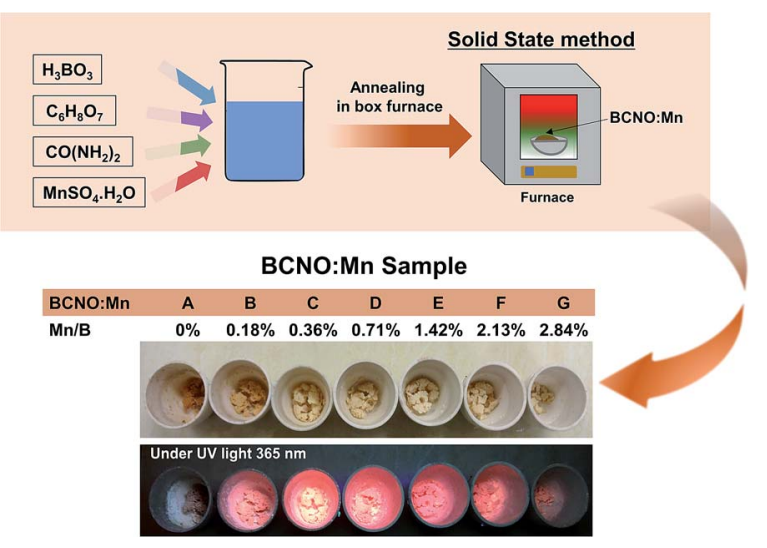

Fig. 1 Schematic of BCNO:Mn synthetic process. The lower image shows the as-prepared BCNO:Mn phosphors synthesized at $550{ }^{\circ} \mathrm{C}$ with various $\mathrm{Mn}$ concentrations. morphologies of the prepared samples were observed using a scanning electron microscope (SEM, JEOL JCM-6000 Benchtop, Japan) at an operating voltage of $15 \mathrm{kV}$. The elemental mapping of the prepared samples was carried out with an energy dispersive X-ray spectroscope (EDXs JEOL JED-2300, Japan). The PL properties, PLE intensity and luminescence decay curves of the samples were characterized using a spectrofluorophotometer (Carry Eclipse, Agilent Ltd., Australia) equipped with a xenon laser source at room temperature.

\section{Results and discussion}

\section{Structural and optical properties of BCNO:Mn phosphor material}

Preparation of BCNO from citric acid, boric acid and urea via a solid-state phase method has been reported; it exhibits blue photoluminescence under UV excitation. ${ }^{\mathbf{1 4}, 15}$ Herein, by adding manganese(II) sulfate monohydrate, with $0.18 \%$ to $2.84 \% \mathrm{Mn} / \mathrm{B}$ ratios (denoted as BCNO:Mn B-G) at various synthesis temperatures, the BCNO:Mn exhibited strong red photoluminescence under $365 \mathrm{~nm}$ UV lamp excitation, as shown in Fig. 1.

A general overview of the structure of the BCNO:Mn samples under various conditions was obtained using FTIR and XRD, as shown in Fig. 2. The FTIR spectra (Fig. 2a) show the absorption peaks of various vibration modes in the $500-4000 \mathrm{~cm}^{-1}$ region for BCNO:Mn samples with various $\mathrm{Mn}$ concentrations. The B-N linkage, vibration at $\sim 789 \mathrm{~cm}^{-1}$ for the $\mathrm{B}-\mathrm{N}-\mathrm{B}$ vibration and $\sim 1400 \mathrm{~cm}^{-1}$ for $\mathrm{B}-\mathrm{N}$ stretching ${ }^{\mathbf{1 6 - 1 8}}$ were prominent in all the samples. The absorption peaks at $\sim 980 \mathrm{~cm}^{-1}, \sim 1010 \mathrm{~cm}^{-1}$, and $\sim 1200 \mathrm{~cm}^{-1}$ correspond to the $\mathrm{N}-\mathrm{B}-\mathrm{O}$ vibration, $\mathrm{B}-\mathrm{O}-\mathrm{B}$, and $\mathrm{B}-\mathrm{O}$ bonds, respectively. ${ }^{19}$ In addition, the absorption peaks at $\sim 1700 \mathrm{~cm}^{-1}, \sim 2230 \mathrm{~cm}^{-1}$, and $3200 \mathrm{~cm}^{-1}$ were induced by the $\mathrm{C}=\mathrm{N}, \mathrm{C} \equiv \mathrm{N}$, and $\mathrm{O}-\mathrm{H}$ stretching vibrations, respectively. The presence of the same vibrations in all the samples indicates the appropriate structure in all BCNO:Mn samples at various Mn concentrations.

XRD patterns showing the crystal structure of BCNO:Mn D at various synthesis temperatures are shown in Fig. 2b. The diffraction peaks of BCNO:Mn D indicate the existence of $\mathrm{B}_{2} \mathrm{O}_{3}$ and $\mathrm{BN}$ phases, which is similar to previous reports..$^{14,15,20}$ The $\mathrm{B}_{2} \mathrm{O}_{3}$ is shown by a characteristic peak centered at $14.7^{\circ}$,
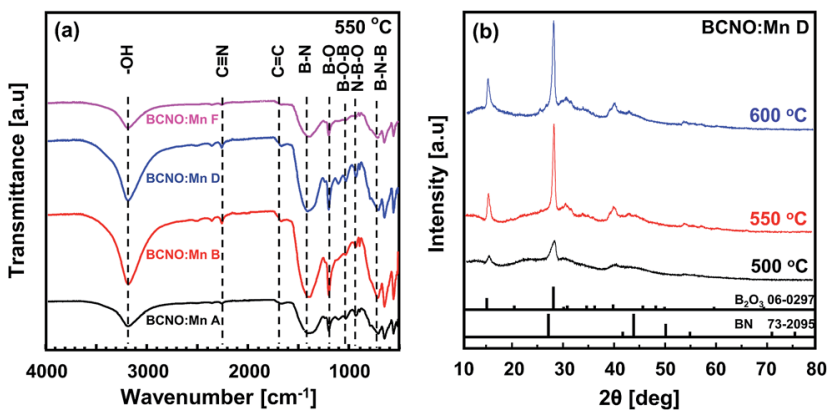

Fig. 2 (a) FTIR spectra of BCNO:Mn samples synthesized at $550{ }^{\circ} \mathrm{C}$ at various $M n$ concentrations; (b) XRD patterns of BCNO:Mn D samples synthesized at various temperatures. 


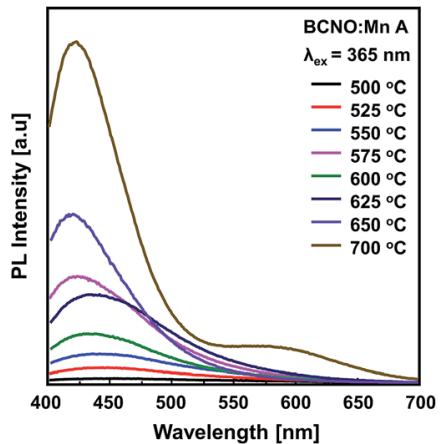

Fig. 3 PL spectra of BCNO:Mn A (undoped BCNO) synthesized at various temperatures under UV light excitation at $365 \mathrm{~nm}$.

whereas $27.8^{\circ}$ belongs to the (111) and (310) of cubic $\mathrm{B}_{2} \mathrm{O}_{3}$ (JCPDS card no. 06-0297), respectively. ${ }^{\mathbf{1 4 , 1 5 2 0}}$ The BN phase, which corresponds to turbostratic BN (t-BN) (JCPDS card no. 732095), is shown by the characteristic peak centered at $27^{\circ}$ and $43^{\circ}$, belonging to (002) and (10) (unresolved (100) and (101) planes for h-BN), respectively. ${ }^{\mathbf{1 4 , 1 5}}$ This result indicates that BCNO was successfully synthesized via the solid state phase method. The t-BN on BCNO:Mn may have originated from the exothermic reaction of urea with boric acid or $\mathrm{B}_{2} \mathrm{O}_{3}$ with $\mathrm{NH}_{3}$. The presence of $\mathrm{B}_{2} \mathrm{O}_{3}$ is more dominant than the t-BN phase due to volatilization of urea during the reaction under ambient atmosphere. $^{3}$ The PL spectra of the BCNO:Mn A (undoped $\mathrm{BCNO})$ at various synthesis temperatures $\left(500-700{ }^{\circ} \mathrm{C}\right)$ under excitation at $365 \mathrm{~nm}$ are shown in Fig. 3. The PL spectra of BCNO:Mn A synthesized at $500-650{ }^{\circ} \mathrm{C}$ shows a single emission peak in the $415-450 \mathrm{~nm}$ range, i.e. a blue emission. The blue emission is thought to arise from closed-shell $\mathrm{BO}^{-}$and $\mathrm{BO}_{2}{ }^{-}$ anions that act as a luminescence center. ${ }^{2}$ Moreover, from the BCNO:Mn A synthesized at $700{ }^{\circ} \mathrm{C}$, not only a blue emission $(420 \mathrm{~nm})$ but also a weak near red emission $(\sim 580 \mathrm{~nm})$ was observed. The increase of the synthesis temperature of BCNO may lead to $\mathrm{C}$ impurities on the lattice that would serve a new energy level around $2 \mathrm{eV}$, below the conduction band of $\mathrm{BN}^{7}$ Thus, this would increase the transition probability of trapped electrons from the $\mathrm{N}$ vacancy level to the $\mathrm{C}$ impurities level. However, the increase in synthesis temperature provides a strong blue emission rather than a red emission.

\section{Effect of Mn concentrations on PL properties of BCNO:Mn phosphor}

The PL spectra of the BCNO:Mn samples synthesized at $550{ }^{\circ} \mathrm{C}$ at various $\mathrm{Mn}$ concentrations are shown in Fig. 4a. Initially, without Mn-doping, the BCNO exhibited a low blue emission, centered at $450 \mathrm{~nm}$ under UV light excitation at $365 \mathrm{~nm}$. The blue emission may originate from closed-shell $\mathrm{BO}^{-}$and $\mathrm{BO}_{2}$ anions that act as a luminescence center. ${ }^{2}$ The addition of $\mathrm{Mn}$ atoms led to a gradual decrease of the blue emission and dramatically increased the red emission, indicating the existence of $\mathrm{Mn}$ in the BCNO lattice. The red emission of the samples became intense and reached a maximum PL intensity for BCNO:Mn D with a peak centered at $620 \mathrm{~nm}$. The red
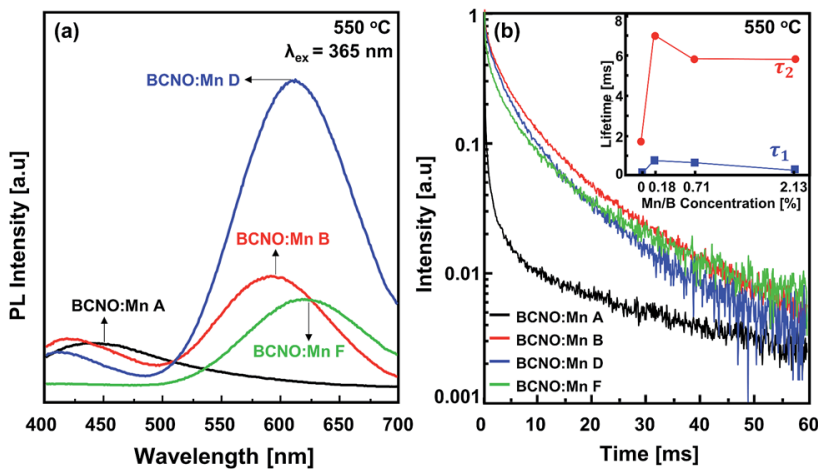

Fig. 4 BCNO:Mn synthesized at $550{ }^{\circ} \mathrm{C}$ at various $\mathrm{Mn}$ concentrations: (a) PL spectra under UV excitation at $365 \mathrm{~nm}$; (b) decay curve ( $\lambda_{\text {ex }}=$ $365 \mathrm{~nm}, \lambda_{\mathrm{em}}=425 \mathrm{~nm}$ for BCNO:Mn A, $620 \mathrm{~nm}$ for BCNO:Mn B,D,F); inset of (b) lifetime of BCNO samples.

emission peak was redshifted as the Mn concentration was increased. This phenomenon was also observed for other phosphors with $\mathrm{Mn}$ as a dopant..$^{\mathbf{9 1 0 , 2 1 , 2 2}}$ This may be related to the stronger crystal field strength due to shortened $\mathrm{Mn}-\mathrm{O}$ distance. $^{22}$ Then, the red PL intensity decreased for BCNO:Mn E (higher $\mathrm{Mn} / \mathrm{B}$ ratio) significantly, which may be due to concentration quenching. ${ }^{21}$

In order to further validate the existence of $\mathrm{Mn}$ on the BCNO lattice, the decay curve of the BCNO:Mn samples was investigated. As described by Blasse, ${ }^{23}$ the decay behavior of BCNO:Mn can be expressed as follows:

$$
I=I_{01} \exp \left(-\frac{t}{\tau_{1}}\right)+I_{02} \exp \left(-\frac{t}{\tau_{2}}\right)+C
$$

where $I$, and $I_{01}, I_{02}$ are the luminescence intensity at time $t$ and 0 , respectively, and $\tau$ is the luminescence lifetime. Fig. $4 \mathrm{~b}$ shows the decay curve of all samples excited at $365 \mathrm{~nm}$ and monitored at $425 \mathrm{~nm}$ for BCNO:Mn A and $620 \mathrm{~nm}$ for other samples. The double exponential fitting indicated that there were at least two luminescence centers, which may be ascribed to the BCNO lattice and Mn dopant. ${ }^{21,22}$ The existence of Mn on the BCNO lattice dramatically elongated the lifetimes of BCNO:Mn compared to undoped BCNO $\left(\tau_{1}: 0.05 \mathrm{~ms}\right.$ to $0.738 \mathrm{~ms}$ and $\tau_{2}$ : $1.62 \mathrm{~ms}$ to $6.97 \mathrm{~ms}$ ), suggesting the presence of additional deexcitation pathways due to the Mn dopant. ${ }^{23}$

Morphological observation and elemental mapping of BCNO:Mn at various $\mathrm{Mn}$ concentrations was performed by scanning electron microscopy (SEM) with EDXS, and the results are shown in Table 1. The SEM images revealed no significant difference in the morphology between Mn:BCNO A (undoped BCNO) and BCNO:Mn at various concentrations. All samples were irregularly shaped and closely attached to each other. The elemental mapping results showed that the prepared samples contained B, C, N, O, and Mn without any contaminants. Welldistributed color intensities and appropriate $\mathrm{Mn}$ atomic percentages of the samples confirmed that $\mathrm{Mn}$ acted as a dopant on the BCNO phosphor. A low $\mathrm{N}$ atomic percentage of a sample indicates that the sample appropriately tends to a $\mathrm{B}_{2} \mathrm{O}_{3}$ structure rather than h-BN. This is reasonable for BCNO 
Table 1 SEM and elemental mapping image of BCNO:Mn synthesized at $550{ }^{\circ} \mathrm{C}$ with various $\mathrm{Mn}$ concentrations

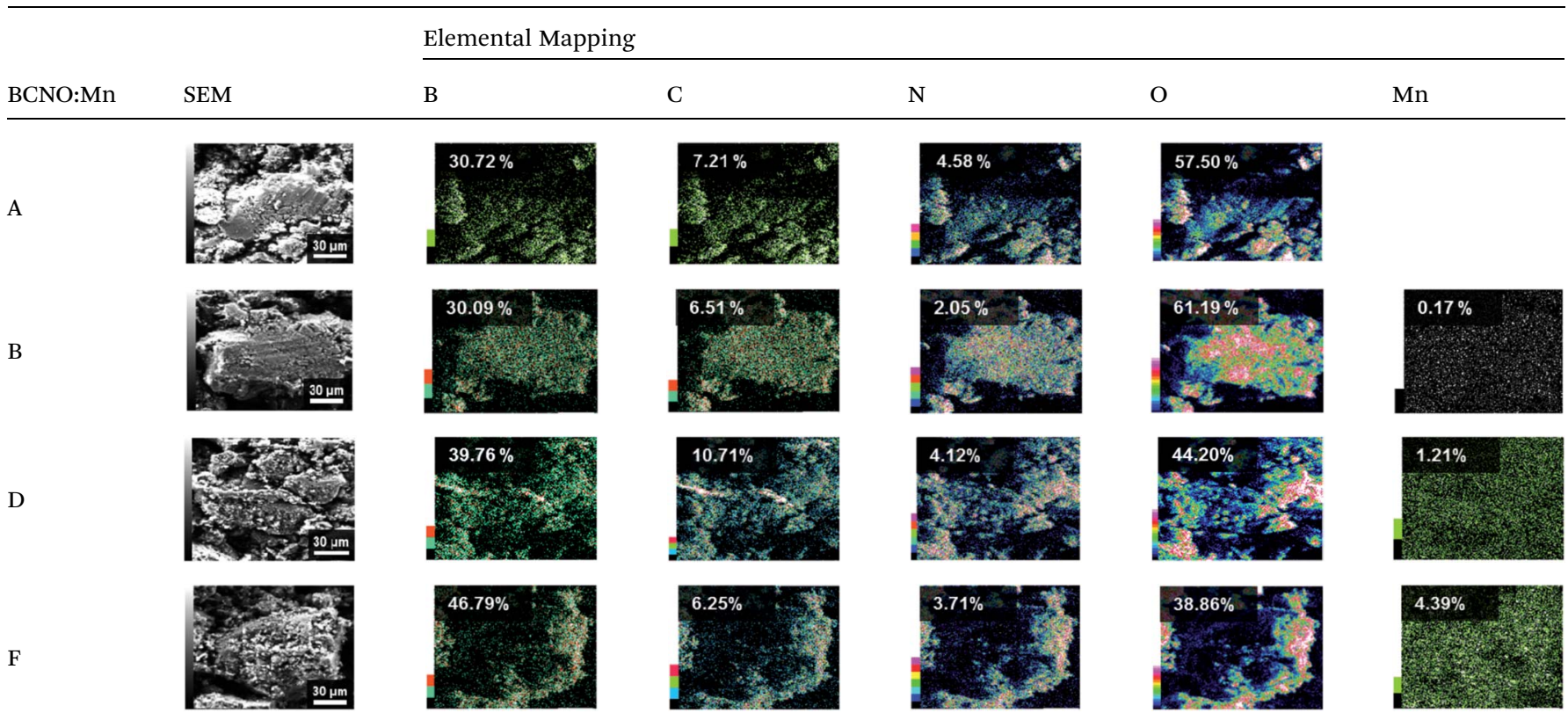

synthesized at $550{ }^{\circ} \mathrm{C}$ due to the high formation energy of h-BN. ${ }^{24}$

\section{Effect of synthesis temperature on PL of BCNO:Mn}

Based on the variation of the Mn concentration, BCNO:Mn D was selected as a representative sample for further investigating the influence of synthesis temperature on the PL. The PL spectra of the BCNO:Mn D samples synthesized at various temperatures are shown in Fig. 5a. The PL spectra showed two emission peaks in the blue range $(\sim 420 \mathrm{~nm})$ and red range $(\sim 620 \mathrm{~nm})$, confirming that the samples consisted of BCNO in the presence of Mn dopant. The red emission peak was shifted toward shorter wavelengths with increasing temperature, which may have been related to changing $\mathrm{C} / \mathrm{B}$ or $\mathrm{C} / \mathrm{N}$ content., ${ }^{2,14,20}$ However, further investigation is still needed. The red emission peak for BCNO:Mn synthesized at 500-600 ${ }^{\circ} \mathrm{C}$ showed a predominant red emission, while starting from $650{ }^{\circ} \mathrm{C}$, the blue emission became predominant, indicating not only the $\mathrm{Mn}$ concentration but also the synthesis temperature plays an important role in the red luminescence of the BCNO phosphor.

The decay curves of the BCNO:Mn samples (Fig. 5b) show a slight decrement in BCNO:Mn D lifetime at various synthesis temperatures, indicating appropriate de-excitation pathways due to the same BCNO:Mn composition.

Despite their lifetime being only weakly influenced, the structure of the BCNO:Mn samples was strongly influenced by the synthesis temperature. As shown in Fig. $2 \mathrm{~b}$, the intensity of each peak in the XRD results tended to increase along with the increase in temperature, which indicates that the BCNO structure was improved. ${ }^{20}$ Details of the XRD patterns of the BCNO:Mn D at $14.7^{\circ}$ and $27.8^{\circ}$ belonging to (111) and (310) of cubic $\mathrm{B}_{2} \mathrm{O}_{3}$ are shown in Fig. $5 \mathrm{c}$ and d. As the synthesis temperature was increased, the diffraction patterns shifted to a higher angle and then reshifted to a lower angle. This shifting is attributed to the transformation of the lattice size of BCNO:Mn due to Mn incorporation. ${ }^{21}$
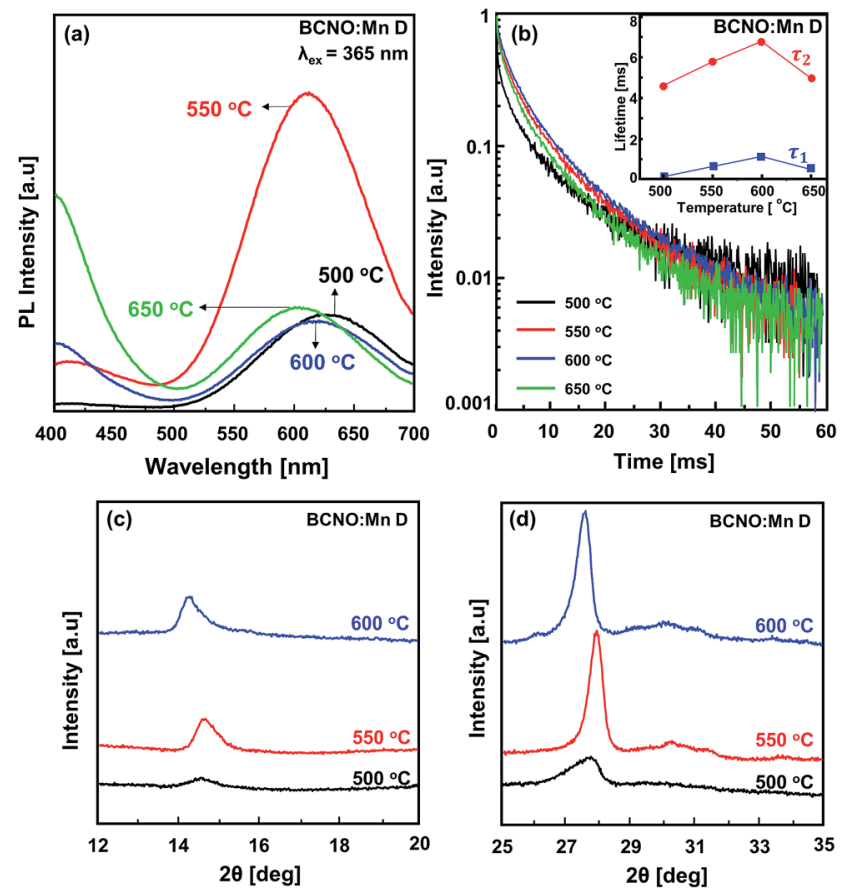

Fig. 5 The BCNO:Mn D synthesized at various temperatures: (a) PL spectra under $365 \mathrm{~nm}$ UV excitation; (b) the decay curve $\left(\lambda_{\text {ex }}=365 \mathrm{~nm}\right.$, $\lambda_{\mathrm{em}}=620 \mathrm{~nm}$ ), the inset (b) lifetime of BCNO sample; (c and d) the XRD pattern details, as shown in Fig. $2 b$. 


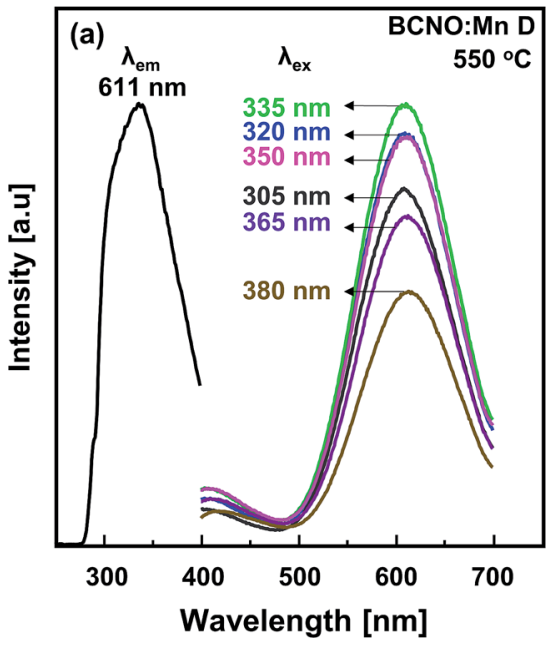

(b)

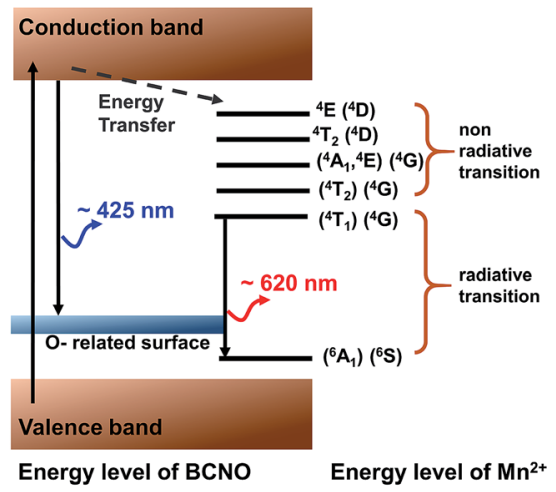

Fig. 6 (a) The PLE and PL of BCNO:Mn D synthesized at $550^{\circ} \mathrm{C}$; (b) idealized energy level scheme of BCNO:Mn phosphors (assuming Mn in form $\mathrm{Mn}^{2+}$ pure tetrahedral point symmetry $\left.\left(T_{\mathrm{d}}\right)\right)$.

\section{PL mechanism}

Fig. 6a shows the PL and PLE spectra of BCNO:Mn D synthesized at $550{ }^{\circ} \mathrm{C}$. The PL spectra show excitation independence with predominant emission peak centers at $611 \mathrm{~nm}$. The excitation independence may be induced by the O-related surface ${ }^{26}$ as observed in the EDXS results (Table 1). Normally, when $\mathrm{Mn}^{2+}$ is incorporated into a phosphor host lattice, the emission spectra are strongly affected by the $\mathrm{Mn}^{2+}$ incorporation in the host lattice structure. A green or yellow emission has been observed for $\mathrm{Mn}^{2+}$ incorporated into a tetrahedral coordination environment, as shown by $\mathrm{ZnGa}_{2} \mathrm{O}_{4}: \mathrm{Mn}^{2+}\left(\lambda_{\text {em }}: 502 \mathrm{~nm}\right){ }^{25}$ $\mathrm{ZnS}: \mathrm{Mn}^{2+}\left(\lambda_{\mathrm{em}}: 580 \mathrm{~nm}\right)$, SrZnO: $\mathrm{Mn}^{2+}\left(\lambda_{\mathrm{em}}: 575 \mathrm{~nm}\right),{ }^{27}$ etc. On the other hand, a red emission has been observed for $\mathrm{Mn}^{2+}$ incorporated into an octahedral coordination environment, as shown by $\mathrm{LiAlO}_{2}: \mathrm{Mn}^{2+}\left(\lambda_{\text {em }}: 670 \mathrm{~nm}\right),{ }^{9} \mathrm{Ca}_{9} \mathrm{Lu}\left(\mathrm{PO}_{4}\right)^{7}: \mathrm{Mn}^{2+}\left(\lambda_{\text {em }}\right.$ : $645 \mathrm{~nm}),{ }^{28}$ etc. However, the evident lattice structure of BCNO has not been reported, and thus the unclear PL mechanism of emission was based on the host lattice structure.

Another PL mechanism, based on the Tanabe-Sugano diagram, is illustrated in Fig. 6b. The observed red emission of BCNO:Mn may be ascribed to the ${ }^{4} \mathrm{~T}_{1}\left({ }^{4} \mathrm{G}\right) \rightarrow{ }^{6} \mathrm{~A}_{1}\left({ }^{6} \mathrm{~S}\right)$ transition of $\mathrm{Mn}^{2+}$ incorporated into the BCNO host lattice. It is reasonable to idealize that the $\mathrm{Mn}$ atoms that originated from manganese(II) sulfate monohydrate did not go through oxidation during synthesis. The incorporation of the larger $\mathrm{Mn}^{2+}$ ions (ionic radii $83 \mathrm{pm}$ ) in the BCNO lattice increases the BCNO lattice constant. The expanding crystal will reduce the orbital overlap of neighboring atoms. ${ }^{\mathbf{1 0 , 2 9 , 3 0}}$ As a consequence, orbital splitting will occur, serving a new energy level within the BCNO bandgap. In addition, as a transition metal ion, $\mathrm{Mn}^{2+}$ has an incompletely filled d-shell, which causes a strong crystal field around its ions in the BCNO lattice that can generate the transfer energy from lattice to the $\mathrm{Mn}^{2+}$ level..$^{24,28}$ However, the BCNO structure itself has a luminescence center that exhibits a blue emission, whereas the $\mathrm{Mn}^{2+}$ level has a luminescence center that exhibits a red emission. Moreover, the competition between both luminescence centers should be seen as a function of Mn concentration and synthesis temperature.

The existence of Mn dopant on the BCNO lattice acts as a new luminescence center that generates a red emission. The decrement of the red PL intensity after reaching the optimum Mn concentration is due to the quenching concentration, as reported in the Mn-doped phosphor case. This is reasonable because the increase of the Mn concentration forces a wider orbital overlap that leads to effective energy transfer between the Mn atoms. Therefore, the excited electrons will pass through far away from the excitation site, leading to a nonradiative transition. In addition, the decrement of the red PL intensity after reaching the optimum synthesis temperature may be due to the improved BCNO lattice as a blue luminescence center. However, further investigation is needed to elucidate the real competition between both luminescence centers.

\section{Conclusion}

A red luminescence BCNO:Mn phosphor was successfully synthesized for the first time via a solid state method. A series of experiments was conducted to explore the effects of $\mathrm{Mn}$ concentration and synthesis temperature on the PL properties. The phosphors were characterized via electron microscopy, X-ray diffraction, FTIR spectroscopy, EDXS, and PL, PLE and time-resolved luminescence spectroscopy. The BCNO:Mn exhibited two peaks, i.e. a predominant peak in the red range and a minor peak in the blue range. The blue emission may originate from closed-shell $\mathrm{BO}^{-}$and $\mathrm{BO}^{2-}$ anions that act as luminescence center. Moreover, the red emission of BCNO:Mn may be ascribed to the ${ }^{4} \mathrm{~T}_{1}\left({ }^{4} \mathrm{G}\right) \rightarrow{ }^{6} \mathrm{~A}_{1}\left({ }^{6} \mathrm{~S}\right)$ transition of $\mathrm{Mn}^{2+}$ incorporated into the BCNO host lattice. The optimum red PL properties (emission $611 \mathrm{~nm}$ under $365 \mathrm{~nm}$ excitation) were obtained from BCNO:Mn with a $0.71 \% \mathrm{~mol} / \mathrm{mol} \mathrm{Mn} / \mathrm{B}$ molar ratio synthesized at $550{ }^{\circ} \mathrm{C}$. 


\section{Acknowledgements}

This study was partly supported by a research grant Penelitian Unggul Integrasi Keilmuan (DIKTIS PUIK/37/2016) from the Ministry of Religious Affairs, Republic of Indonesia and Riset Desentralisasi PUPT (PN-7-11-2016) from the Indonesian Directorate General of Higher Education (DIKTI).

\section{References}

1 T. Ogi, Y. Kaihatsu, F. Iskandar, W. N. Wang and K. Okuyama, Adv. Mater., 2008, 20, 3235-3238.

2 W. N. Wang, T. Ogi, Y. Kaihatsu, F. Iskandar and K. Okuyama, J. Mater. Chem., 2011, 21, 5183-5189.

3 X. Liu, S. Ye, Y. Qiao, G. Dong, Q. Zhang and J. Qiu, Chem. Commun., 2009, 4073-4075, DOI: 10.1039/b904567h.

4 X. Zhang, L. Li, Z. Lu, J. Lin, X. Xu, Y. Ma, X. Yang, F. Meng, J. Zhao and C. Tang, J. Am. Ceram. Soc., 2014, 97, 246-250.

5 B. W. Nuryadin, E. C. Septia, F. Iskandar, T. Ogi, K. Okuyama, M. Abdullah and Khairurrijal, Adv. Mater. Res., 2014, 896, 464-467.

6 Y. Kaihatsu, W.-N. Wang, F. Iskandar, T. Ogi and K. Okuyama, J. Electrochem. Soc., 2010, 157, J329.

7 X. Zhang, X. Jia, H. Liu, Z. Lu, X. Ma, F. Meng, J. Zhao and C. Tang, RSC Adv., 2015, 5, 40864-40871.

8 Y. Kang, Z. Y. Chu, T. Ma, W. P. Li, D. J. Zhang and X. Y. Tang, Optoelectron. Lett., 2016, 12, 1-4.

9 M. Aoyama, Y. Amano, K. Inoue, S. Honda, S. Hashimoto and Y. Iwamoto, J. Lumin., 2013, 136, 411-414.

10 P. Li, M. Peng, L. Wondraczek, Y. Zhao and B. Viana, J. Mater. Chem. C, 2015, 3, 3406.

11 N. J. Cherepy, S. A. Payne, N. M. Harvey, D. Åberg, Z. M. Seeley, K. S. Holliday, I. C. Tran, F. Zhou, H. P. Martinez and J. M. Demeyer, Opt. Mater., 2016, 54, 14-21.

12 T. Ogi, H. Iwasaki, A. B. D. Nandiyanto, F. Iskandar, W.-N. Wang and K. Okuyama, J. Mater. Chem. C, 2014, 2, 4297-4303.

13 X. Zhang, J. Yu, Z. Lu, H. Liu, X. Jia, C. Ren, X. Yang, F. Meng and C. Tang, J. Lumin., 2016, 176, 283-291.
14 B. W. Nuryadin, T. P. Pratiwi, F. Iskandar, M. Abdullah, K. Khairurrijal, T. Ogi and K. Okuyama, Adv. Powder Technol., 2014, 25, 891-895.

15 H. Iwasaki, T. Ogi, F. Iskandar, K. Aishima and K. Okuyama, J. Lumin., 2015, 166, 148-155.

16 C. Ren, X. Zhang, L. Zhou, Z. Lu, J. Lin, X. Xu, L. Li, X. Zhang, Y. Xue, F. Meng, J. Zhao and C. Tang, J. Lumin., 2014, 153, 338-342.

17 F. Lu, X. Zhang, Z. Lu and C. Tang, J. Lumin., 2014, 149, 231235.

18 X. Zhang, Z. Lu, H. Liu, J. Lin, X. Xu, F. Meng, J. Zhao and C. Tang, J. Mater. Chem. C, 2015, 3, 3311-3317.

19 E. D. Rivera-Tapia, C. A. Fajardo, A. J. Ávila-Vega, C. F. Ávila, F. M. Sánchez-Arévalo, I. Chango-Villacís, F. J. QuirozChávez, J. Santoyo-Salazar and R. C. Dante, Fullerenes, Nanotubes, Carbon Nanostruct., 2016, 24, 8-12.

20 I. D. Faryuni, B. W. Nuryadin, F. Iskandar, M. Abdullah, Khairurrijal, T. Ogi and K. Okuyama, J. Lumin., 2014, 148, 165-168.

21 P. Li, M. Peng, M. Wondraczek, Y. Zhao and B. Viana, J. Mater. Chem. C, 2015, 3, 3406-3415.

22 L. Shi, H. Yanlin and J. S. Hyo, J. Phys. Chem. A, 2010, 114, 6927-6934.

23 G. Blasse and B. Grabmaier, in Luminescent Materials, Springer, 1994, pp. 91-107.

24 A. Yamanaka and S. Okada, Sci. Rep., 2016, 6, 30653.

25 J. S. Kim, J. S. Kim, T. W. Kim, S. M. Kim and H. L. Park, Appl. Phys. Lett., 2005, 86, 231909.

26 L. Tang, R. Ji, X. Li, K. S. Teng and S. P. Lau, Part. Part. Syst. Charact., 2013, 30, 523-531.

27 S. Kubota, T. Oyama, H. Yamane and M. Shimada, Chem. Mater., 2003, 15, 3403-3405.

28 N. Guo, Y. Huang, H. You, M. Yang, Y. Song, K. Liu and Y. Zheng, Inorg. Chem., 2010, 49, 10907-10913.

29 G. Li, D. Geng, M. Shang, C. Peng, Z. Cheng and J. Lin, J. Mater. Chem., 2011, 21, 13334.

30 Q. Zhang, H. Ni and L. Wang, Appl. Phys. A: Mater. Sci. Process., 2013, 114, 883-889. 